\title{
UN BIOMBO MEXICANO DEL SIGLO XVIII
}

\author{
$\mathbf{P} \mathbf{O} \mathbf{R}$
}

\section{SALVADOR MORENO}

I os mexicanos cultos que visitan Sevilla, suelen enterarse que en la L casa de la Marquesa de Lebrija - calle Cuna 18 - se guardan y atesoran mosaicos y objetos procedentes de las ruinas de Itálica.

La casa, habitada actualmente por los Condes de Bustillo; abre sus puertas a quienes lo solicitan, y al visitante mexicano, apenas traspasada la cancela de hierro, le sorprende agradablemente encontrar frente a él un hermoso biombo mexicano del siglo xvirr.

Lo que hasta hoy se ignoraba es que en las habitaciones privadas de la casa existiera otro biombo mexicano, igualmente esplétidido y muy semejante; biombo que hemos tenido la suerte de admirar $y$-del que no se ha publicado nada hasta hoy, según nos dice el Conde de Bustillo, don Pedro Armero Manjón, en carta del 16 de noviembre de 1957: "Del que está en el comedor nadie ha escrito nada."

Por el propio Conde sabemos que lo "descubrió" en una habitación en la que su tía, la Marquesa de Lebrija, guardaba objetos aún no clasificados. Sus seis hojas, de casi dos metros de altura, como las del biombo del umbral, están decoradas igualmente con representaciones típicas de la vida mexicana de la épocä, escenas que también transcurren en los lugares más importantes y famosos de la ciudad de México.

En el primer biombo, el doble recorrido - ya que cada hoja está dividida en dos cuerpos - va del "Puente de la Mariscala" hasta la "Alameda Central", siguiendo "La Arquería por donde entra la Agua á México", y de "El Peñón" hasta "El Cerro de Nuestra Señora de Guadalupe", pasando por la "Calzada" del mismo nombre. 
En el segundo biombo los recorridos van desde los alrededores de "El Peñón de San Angel" a "La Catedral", por "La Calzada de San Antonio Abad", y de los alrededores de "La Piedad" hasta "El Cerro de Chapultepeque", pasando por "El Salto de el Agua" y la "Cañería de Betlem". Durante el trayecto se precisan, con sus nombres, no sólo los monumentos y lugares, sino también los paseantes y mercaderes que por alli transitan; "Un Indio sacando Pulque de los Magueyes", "Indios serrando", "Indio vendedor de nueces", indio descansando junto a su carga de "Aguardiente de Contravando"... "El Volcán”, "El otro Volcán", "La Laguna de Chalco", "Istapalapa", "Coyoacán", "El Peñón de San Angel", "Paseo de Xamayca", "Mecameca" ... "Canoa de porte", "Canoa de Chalco"... "La Catedral", "EI Real Palacio", "La Iglesia de San Antonio Abad", la iglesia de "La Piedad", "Betlem de las Mochas", "Casa de las Mochas", "Puente de Palacio", "Puente del Correo Mayor"...

Del biombo del zaguán la Marquesa de Lebrija, al hacer la descripción de su casa en un libro publicado en parte por el Conde de Bustillo (Discursos... Imprenta de la Escuela de Artes Gráficas. Sevilla, 1947), dice "Entre ambos patios existe el precioso y original biombo que procede de mi antepasada doña Eduarda Gil de Ledesma, en cuya casa de la calle de San Agustín, de Sanlúcar de Barrameda, estuvo muchos años. Este biombo, graciosamente pintado sobre un rojo que parece laca, está coronado por una cresteria dorada, tallada y calada, debajo de la cual, campean volando en varias y graciosas actitudes, unos pájaros lindísimos de vivos plumajes, que según me dicen son el Quetzal, pájaro sagrado de Méjico (sic). Debajo se ven, divididos en dos zonas, edificios y vistas que aún en México subsisten, y asuntos completamente propios del país, representados por infinitas personas debidamente clasificadas."

Ese mismo primer biombo ha tenido la suerte de ser estudiado, más a fondo, por el señor Enrique Marco Dorta en la importante publicación Archivo Español de Arte (No 62, Madrid, 1944). Al referirse a la parte puramente decorativa, acertadamente dice: "Las figuras que animan el cuadro forman bellas escenas costumbristas, y los fantásticos pájaros que, con casi rigurosa simetria, animan los espacios libres, parecen inspirados por el arte oriental, cuyas influencias llegaron a Méjico por la vía de Manila y Acapulco."

Sugiere Marco Dorta que las iniciales A y $R$ con que están marcadas las "Cargas del Pulque", que transportan algunas mulas, bien podrían ser las del autor de estas pinturas y que "según se desprende de la época 
de los monumentos en él reproducidos", ésta puede corresponder a la de mediados del siglo xviII.

Las citas anteriores que se refieren al primer biombo pueden aplicarse al segundo, por la gran semejanza de ambos, evidentemente pintados por el mismo artista, lo que no sería de extrañar ya que estos valiosos biombos mexicanos fueron muy apreciados como obras de encargo. (Ver Las Artes Industriales en la Nueva España, del Marqués de San Francisco. México, 1923.)

De los biombos mexicanos que se conocen en España uno, decorado con escenas de la conquista, es propiedad del Duque de Almodóvar, de Madrid, y se publicó una fotografía en S. A. Amigos del Arte (Madrid, 1930). El señor Marco Dorta dice haber conocido en Sevilla tres. Uno del siglo xviI, publicado por Diego Angulo Iñiguez en Arte en América y Filipinas (Cuaderno $2^{\circ}$ ). Otro se conserva en el Hospital de la Caridad $y$, finalmente, el que él considera de mayor importancia artística, que es el perteneciente al Conde de Bustillo.

Publicamos, por vez primera, unas fotos del biombo $y$ con estas líneas sólo queremos dejar constancia de su existencia, ya que su interés artístico y su importancia documental e histórica requieren, sin duda, un estudio más minucioso. 
DOI: http://dx.doi.org/10.22201/iie.18703062e.1959.28.663 

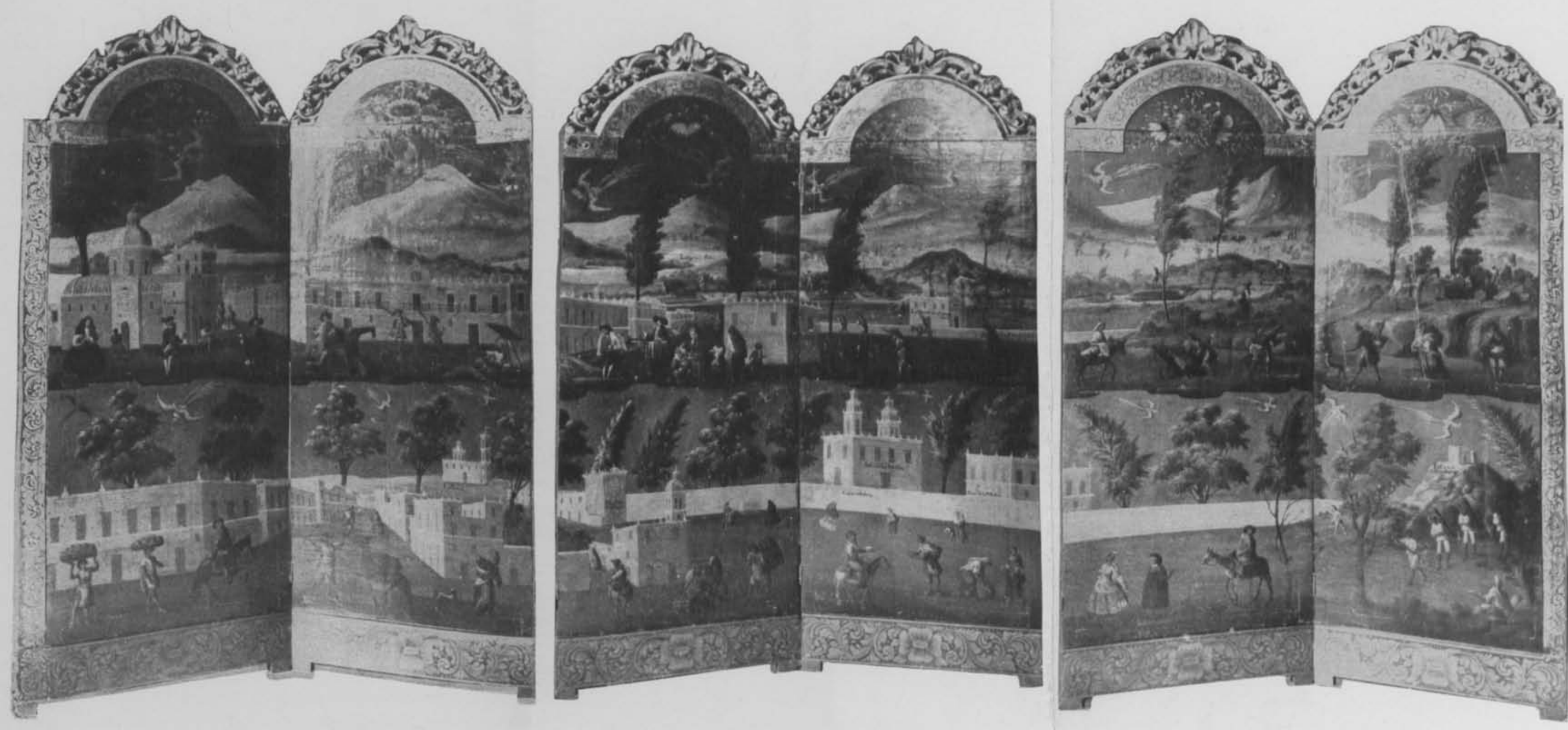